\title{
Th17 Cells Paradoxical Roles in Melanoma and Potential Application in Immunotherapy
}

\author{
Chen Chen and Feng-Hou Gao* \\ Department of Oncology, Shanghai 9th People's Hospital, Shanghai Jiao Tong University School of Medicine, Shanghai, \\ China
}

The progressive infiltration of immune cells is associated with the progression of melanoma. Specifically, Th17 cells in melanoma microenvironment have both antitumor and protumor effects. It is now necessary to understand the contradictory data associated with how Th17 cells play a role in melanoma. This review will summarize the current knowledge regarding the potential mechanisms that may be involved in the effects of Th17 cells in melanoma progression. Currently, since adoptive transferring Th17 cells has been successful in eradicating melanoma in mice, it offers promise for next-generation adoptive cell transfer, as ex vivo expanded stemness-like memory Th17 cells which are induced by distinct cytokines or pharmacologic reagents may be infused

OPEN ACCESS

Edited by: Prashant Trikha,

Nationwide Children's Hospital, United States

Reviewed by:

Amedeo Amedei,

Università degli Studi di Firenze, Italy

Yared Hailemichael,

University of Texas MD Anderson

Cancer Center, United States

*Correspondence:

Feng-Hou Gao

fenghougao@163.com

Specialty section:

This article was submitted to Cancer Immunity and Immunotherapy,

a section of the journal

Frontiers in Immunology

Received: 20 November 2018

Accepted: 22 January 2019

Published: 08 February 2019

Citation:

Chen C and Gao F-H (2019) Th17 Cells Paradoxical Roles in Melanoma and Potential Application in Immunotherapy.

Front. Immunol. 10:187.

doi: 10.3389/fimmu.2019.00187 into melanoma patients to potentiate treatment outcome.

Keywords: Th17 cell, melanoma, tumor microenvironment, immunotherapy, adoptive cell transfer

\section{INTRODUCTION}

Melanoma is a tumor originated from melanocytes, specialized pigmented cells that are mainly resident in the skin $(1,2)$. Worldwide, it is estimated that around 287,723 (1.6\%) cases of all newly diagnosed cancers are cases of melanoma of the skin, and about 60,712 cancer deaths are due to melanoma of the skin, based on cancer statistic carried out in 2018 (3). Melanoma can be cured by surgical resection if it is diagnosed early, and the 5-year survival rate is over $89 \%$ (4). However, once melanoma has spread, it rapidly becomes life-threatening (5).The treatment options for patients with advanced, unresectable, or metastatic melanoma, especially BRAF-V600E/K mutant melanoma which comprises $\sim 50 \%$ of the cases, have changed dramatically over a short period of time (6). BRAF inhibitors (Vemurafenib and Dabrafenib) and MEK inhibitors (Trametinib and Cobimetinib) have been approved by the FDA for treatment of advanced-stage melanoma patients with BRAF-V600-mutant $(7,8)$. In patients with BRAF-mutant, BRAF-inhibitor-refractory disease checkpoint inhibitors against PD-1 (pembrolizumab and nivolumab) and CTLA4 (ipilimumab) have demonstrated efficacy $(6,7,9,10)$. Nevertheless, $10-15 \%$ of patients treated with ipilimumab experienced a range of inflammatory side effects, also called immune-related adverse events (irAE) that even lead to death sometimes $(4,11,12)$. So, development of new therapeutic approaches and optimization of current therapeutic approaches would be of great importance in the field of melanoma therapy research.

Extensive literature describes how immune cells recruited to the tumor microenvironment can exert critical functions in tumor development and progress (13). Specifically, the roles of $\mathrm{T}$ cells in cancer are of great interest. Apart from $\mathrm{CD}^{+}{ }^{+}$cytotoxic $\mathrm{T}$ lymphocytes, $\mathrm{CD} 4^{+}$ $\mathrm{T}$ cells are essential components of cell-mediate immunity. Th17 cells, as a third subset of $\mathrm{CD}_{4}^{+} \mathrm{T}$ cells, are developmentally distinct from $\mathrm{Th} 1$ and $\mathrm{Th} 2$ lineages $(14,15)$. IL- 6 , 
TGF- $\beta$, and IL- $1 \beta$ are required for Th17 cells differentiation from naïve $\mathrm{CD}^{+} \mathrm{T}$ cells and IL-21, IL-23 contribute to their maintenance (16-18). These cytokines induce signal transducer and activator of transcription 3 (STAT3) activation and expression of the major transcription factors of Th17 cells retinoic acid-related orphan receptor (ROR) $\gamma t, \operatorname{ROR} \alpha$ as well as other transcriptional factors $(19,20)$, and then promote expression of IL-17, IL-21, IL-22 (21). It is well known that Th17 cells play an important role in inflammation disease $(22,23)$. And accumulating evidence suggest that Th17 cells present in tumors, including melanoma. Moreover, progressively greater number of infiltrating Th17 cells were appreciated during the development of melanoma from common melanocyte nevi to dysplastic nevi to malignant melanoma (24). Currently, many research groups have made great efforts to reveal the effects of Th17 in melanoma. Herein, we focus on the mechanisms of Th17 cells accumulation and function in melanoma and discuss ways to manipulate Th17 via cytokines and pharmaceutics to potentiate treatment outcomes in patients.

\section{MAJOR MECHANISMS REGULATING TH17 CELL ACCUMULATION AND EXPANSION}

\section{Mechanisms of Th17 Cells Recruitment in Melanoma Microenvironment}

Recent studies have suggested the potential mechanisms responsible for the recruitment of Th17 cells in melanoma microenvironment. Chemokines secreted by melanoma cells and the cells within melanoma microenvironment play an important role in recruiting immune cells with corresponding receptors to melanoma microenvironment. Th17 cells express both Th1associated (CCR2, CXCR3, CCR5, and CXCR6) and Th2associated (CCR4) trafficking receptors. In addition, Th17 cells express non-lymphoid tissue trafficking receptors (CCR4, CCR5, CCR6, CXCR3, and CXCR6) as well as homeostatic chemokine receptors (CD62L, CCR6, CCR7, CXCR4, and CXCR5) that are involved in $\mathrm{T}$ cell migration to lymphoid tissues (25). However, tumor-infiltrating Th17 cells may have different chemokine receptors in different tumor contexts. In melanoma, tumorinfiltrating Th17 cells express CCR2, CCR4, CCR5, CCR6, CCR7, and CXCR3 (26).

Work by Peng's group showed that tumor-derived fibroblasts secreted MCP-1 (known as CCL2), the ligand for CCR2 or CCR4, and RANTES (known as CCL5), the ligand for CCR1, CCR3, or CCR5. And they both mediated the recruitment of Th17 cells in tumor microenvironment (26). When triggering TLR and Nod signaling to increase the expression of MCP-1 and RANTES by melanoma cells and tumor-derived fibroblasts, they found that the chemotactic activity of Th17 cells was enhanced. This result suggests that chemokines, involved in TLR and NOD signaling, secreted by melanoma cells and tumor-derived fibroblasts could lead Th17 cells recruiting to melanoma sites (Figure 1) (26).

Tumor-associated macrophages (TAMs) are also involved in Th17 cells infiltration. Researchers used modified melanomacondition (MCM) to differentiate human monocytes to macrophages and they found that these MCM-induced macrophages strikingly increased CCL2 expression (27). Furthermore, tumor-infiltrating monocytic myeloid-derived suppressor cells (MO-MDSC) and granulocytic myeloid-derived suppressor cells (PMN-MDSC) from B16-bearing mice could produce higher levels of CCL3, CCL4, CCL5 than that in control mice at melanoma sites, especially MO-MDSCs (28). And CCL4/MIP-1 $\beta$, which is produced by immature myeloid cells, could recruit Th17 cells to tumor sites (Figure 1) (29).

\section{Th17 Cells Development, Differentiation, and Expansion in Melanoma Microenvironment}

Tumor cells and tumor-derived fibroblasts promote expansion of human Th17 cells within melanoma by producing proinflammatory cytokines and providing cell-cell contact. When cocultured naïve $\mathrm{CD}^{+}{ }^{+} \mathrm{T}$ cells isolated from human peripheral blood mononuclear cell with melanoma cells and tumor-derived fibroblasts, the percentage of Th17 cells was higher than in the medium alone. Instead, if naïve $\mathrm{CD} 4^{+} \mathrm{T}$ cells were separated from melanoma cells or tumor-derived fibroblasts using the transwell system, the generation of Th17 cells from naïve $\mathrm{CD}^{+} \mathrm{T}$ cells was significantly decreased compared to coculture (26). This indicated that melanoma cells and melanoma associated fibroblast could provide cell-cell contact mechanism to promote the expansion of Th17 cells, but the underlying mechanism remains to be defined.

Cytokines engaged in Th17 cells differentiation and maintenance also contribute to Th17 cells expansion in melanoma. Melanoma cells and tumor-derived fibroblasts could express high levels of IL-1 $\beta$, IL-6, TGF- $\beta$, and IL-23, which provide an optimal proinflammatory cytokine milieu for Th17 cells expansion (26). Apart from melanoma cells and tumor-derived fibroblasts, dendritic cells in melanoma sites could also produce IL-6, TNF- $\alpha$, IL-12p70, and IL-23 (30). In addition, macrophages are abundant leukocytes in melanoma lesions. They express high levels of IL-1 $\beta$ and IL-6, which may also contribute to Th17 cells expansion in melanoma (Figure 1) (31).

\section{PARADOX OF TH17 CELLS FUNCTIONS IN MELANOMA}

Although Th17 cells are prevalent in melanoma microenvironment, the relationship between Th17 cells and tumor immunopathology remains controversial with both antitumor and protumor effects depicted in melanoma (32).

\section{Antitumor Effect of Th17 Cells in Melanoma}

Th17 cells do not express neither granzyme B nor perforin and have no ability to inhibit tumor cells proliferation directly (33, 34). However, increasing evidence suggests that Th17 cells have potent antitumor effects in melanoma. Firstly, the conversion of Th17 cells toward Th1 cells may contribute to the antitumor effect of Th17 cells in melanoma. Expression IFN- $\gamma$ is the main character of these Th17 cells. In metastatic melanoma 


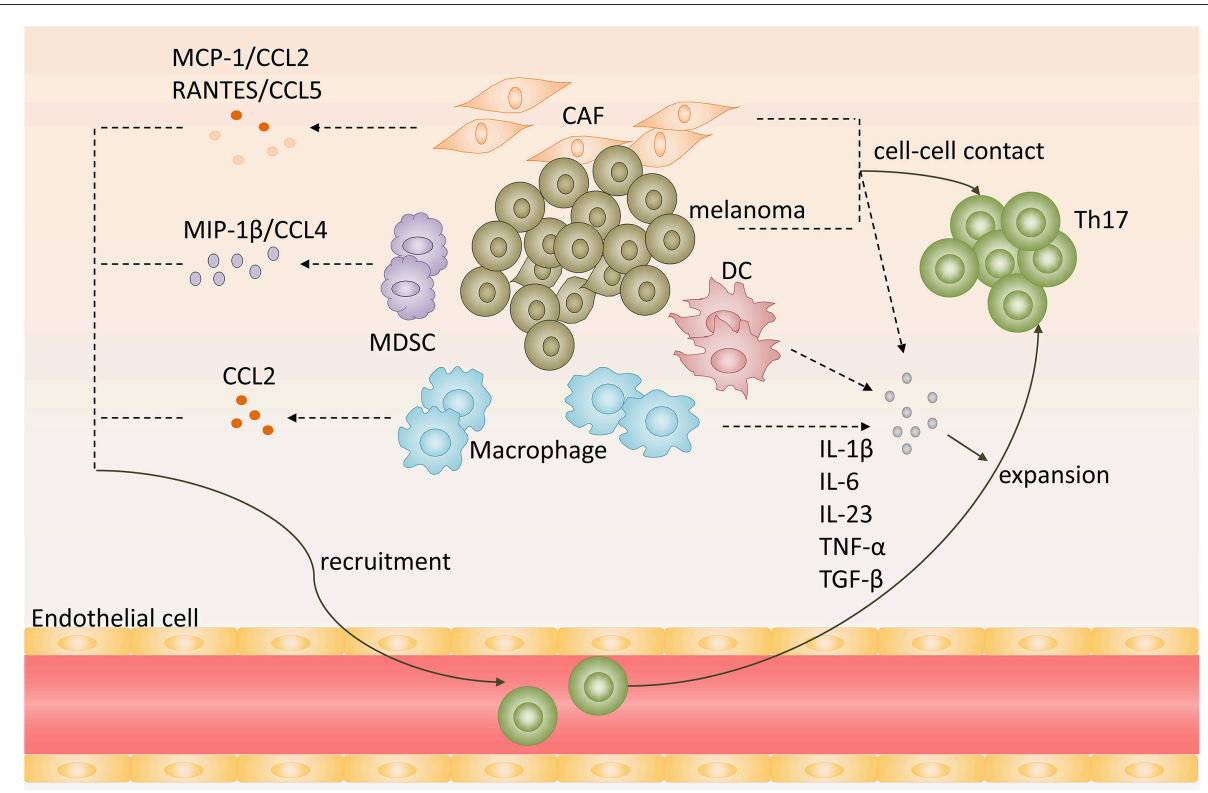

FIGURE 1 | Recruitment, expansion of Th17 cells in melanoma microenvironment. Chemokines, including CCL2, CCL5, CCL4, secreted by melanoma, cancer-associated-fibroblasts (CAF), myeloid-derived suppressor cells (MDSC) or tumor-associated macrophages (TAM), promote Th17 cells recruitment to melanoma. Melanoma cells, CAFs, TAMs, and DCs produce proinflammatory cytokines, such as IL-1 $\beta$, IL-6, IL-23, TNF- $\alpha$, and TGF- $\beta$, and provide cell-cell contact that promote expansion of Th17 cells.

patients characterized by high frequency of Th17 cells and IFN $\gamma$ secreting Th17 cells in peripheral blood before being vaccinated with therapeutic survivin-derived peptide epitopes were more likely to develop survival-specific T-cell reactivity and have higher survival rate than patients with lower frequency of these cells (35). Muranski and coworkers created a transgenic mouse expressing MHC class II-restricted $\mathrm{T}$ cell receptor, in which $\mathrm{CD}^{+} \mathrm{T}$ cells recognize tyrosinase-related protein 1 (TRP-1), an antigen present both in normal melanocytes and B16 melanoma cells. They found that by adoptively transferring tumor specific Th17-polarized cells into large, established B16 melanoma mice, Th17-polarized cells-mediated destruction of advanced melanoma was more effective than that of Th1 cells. And this therapeutic effect was strictly dependent on interferon- $\gamma($ IFN- $\gamma)$ and IL-17 production (36). Deficient IFN- $\gamma$ or IL-17A impaired Th17 cell-mediated melanoma eradication effect (37). These data suggest that Th17 cells plasticity toward Th1-like effector cells may be responsible for Th17 cells antitumor efficiency.

In addition, Martin-Orozco reported that Th17 cells within melanoma microenvironment enhance antitumor effect through recruiting other leukocytes into tumor (38). They found the expression of CCL2/CCL20 was significantly increased in lung cell fraction containing both tumor and

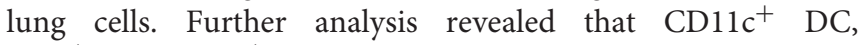
$\mathrm{CD}^{+}$, and $\mathrm{CD}^{+} \mathrm{T}$ cells were greatly increased in Th17treated mouse compared to control mice with metastatic melanoma in lungs (38). These results suggested that tumor-infiltrating Th17 cells stimulated tumor tissues to express CCL2/20 for recruiting various inflammatory leukocytes, such as DCs, $\mathrm{CD}^{+}$, and $\mathrm{CD}^{+} \mathrm{T}$ cells to induce antitumorimmunity $(34,38)$.
Moreover, Th17 cells can exert an antitumor effect by augmenting $\mathrm{CD}^{+} \mathrm{T}$ cells. Martin-Orozco and coworkers found that IL-17A-deficient mice were more likely to develop lung melanoma. Adoptive transferring tumor-specific Th17 cells prevents tumor development. The same group also found that therapy using Th17 cells elicited a remarkable activation of tumor-specific CD8+T cells, which were indispensable for the antitumor effect (38). In a recent study, researchers used ROR $\gamma$ agonist to prime TRP-1 transgenic Th17 cells and Pmel-1 TCR transgenic CD8+ T cells ex vivo and found these cells could effectively regress melanoma compared with those untreated Th17 cells. When co-infused with equal numbers of TRP-1, Th17 cells, and Pmel-1 Tc17 cells in mice with established melanoma, the antitumor effect was greatly enhanced. These data are consistent with previous reports, further confirming that Th17 cells can exert antitumor function by augmenting $\mathrm{CD}^{+} \mathrm{T}$ cells (39). The underlying mechanism of antitumor immunity and CTL activated by Th17 cells may be that Th17 cells stimulated CTL response via IL-2 and peptide/major histocompatibility complex (pMHC)-I, which can be recognized by $\mathrm{CD} 8^{+} \mathrm{T}$ cells and induce $\mathrm{CD}^{+} \mathrm{T}$ activation, based on the fact that IL2 $2^{-/-}$Th17 cells and $\mathrm{K}^{\mathrm{b}-/-}$ (without MHC I) Th17 cells lost their antitumor immunity (Figure 2) (34).

\section{Protumor Effect of Th17 Cells in Melanoma}

Despite some studies demonstrating an antitumor role of Th17 cells in melanoma, several lines of evidence suggest that Th17 cells can also have potent protumor effect in melanoma. BRAF mutation has been attributed to a reduced apoptosis, increased invasiveness and increased metastatic behavior (40). And 
emerging data is revealing the existence of at least two divergent immune phenotypes in melanoma. One type is the Th17 immune phenotype (Class A) with prevalent expression of cancer testis antigens, over-expression of WNT5A, enhanced cyclin activity and poor prognosis. The second class (B) Th1 immune phenotype is associated with a more differentiated status, a higher responsiveness to immune cytokines and better prognosis (41). The question whether these two different phenotypes depend upon the genetic background had been explored by Francesco M Marincola' group. When performing class comparison between BRAF mutant and wild-type metastatic melanoma samples, metastases showing a Th17 phenotype were preferentially BRAF mutated. Moreover, some genes differentially expressed between BRAF mutant and wild-type samples were related to IL-17 pathway. So Th17 cells may also have a potent protumor effect in malignant melanoma $(42,43)$.

Firstly, the expression of IL-17 by Th17 cells has been reported to be associated with tumor angiogenesis in melanoma. In IFN- $\gamma$ deficient mice, the expression levels of vascular endothelial growth factor (VEGF) and MMP9 were upregulated in melanoma cells. The expression of both VEGF and MMP9 were reduced in IFN- $\gamma^{-/-}$IL-17 $-/-$mice (37). These data suggested that IL-17 may promote angiogenesis in melanoma. This has also been confirmed by Yan's laboratory. They found that expression levels of CD31 and MMP9 were strikingly lower in tumor tissues treated with Ad-siIL17 than control. In addition, VEGF was down regulated when inhibiting IL-17A in tumor tissue (44). The underlying mechanism may be that IL-17 promote STAT3 activity via increasing its phosphorylation in melanoma cells and epithelial cells (45).

Secondly, Th17 cells promote tumor proliferation and survival. Lin Wang group reported that IL-17 enhanced melanoma growth due to its direct effects on IL-17 receptors expressing cells, such as melanoma cells, fibroblasts, endothelial cells, and DCs, via promoting their secretion of IL-6. And then IL-6 activated oncogenic STAT3 in melanoma cells and increased expression of prosurvival genes, such as Bcl-2, Bclxl. Therefore, Th17 cells can promote melanoma growth via IL-6-Stat3 pathway (45).

In addition, another mechanism involved in the Th17 cells protumor effect in melanoma may be the Th17/Tregs plasticity in melanoma microenvironment. Th17 cells can function as regulatory cells with the ability to suppress antitumor immunity. Th17 cells undergo lineage conversion into Tregs $(46,47)$. And this conversion results in the intermediate phenotypes that coexpress transcript factors Foxp3 and ROR $\gamma \mathrm{t}$ $(47,48)$. Tumor infiltrating Th17 cells could secrete moderate amounts of IL-10 and TGF- $\beta 1$ after CD3 Ab stimulation and express Treg cell markers Foxp3, CD25, and CTLA4 (26). These results suggested that tumor-infiltrating Th17 cells may have a dual function performing both effector and regulatory roles in melanoma microenvironment. Thus, Th17 cells may contribute to immunopathogenesis of melanoma. The underlying mechanism may involve tumor-infiltrating myeloidderived suppressor cells, which contribute to the Th17-toTreg conversion via secretion of TGF- $\beta$ and retinoic acid (Figure 2) (49).

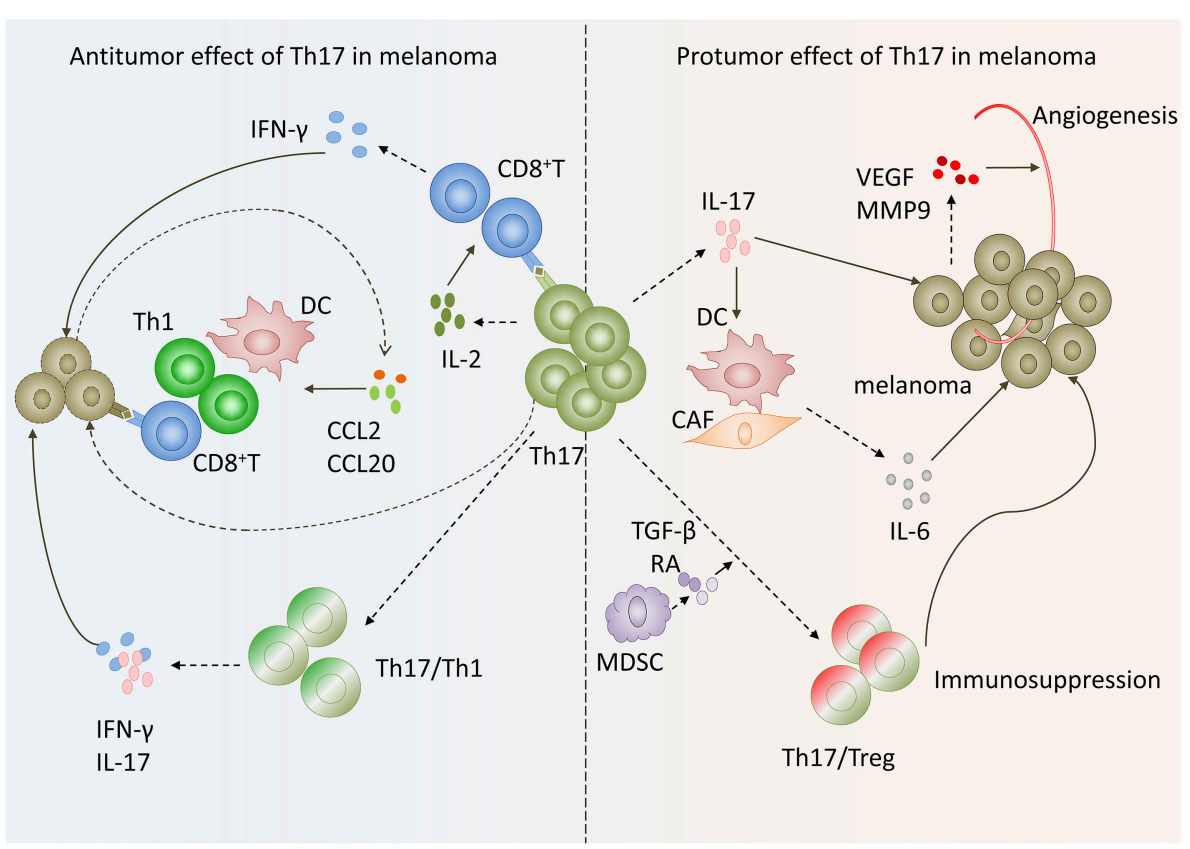

FIGURE 2 | Paradox of Th17 cells functions in melanoma. On the one hand, Th17 cells in melanoma exert antitumoral function via inducing effector cells recruitment and activating tumor-specific cytotoxic CD8+T cells as well as transform to Th1 phenotype. On the other hand, Th17 cells exhibit protumor function by promoting angiogenesis, melanoma cells proliferation and phenotype change toward Tregs. 


\section{BASIC STRATEGIES OF ADOPTIVE TRANSFERRING TH17 CELLS IN MELANOMA}

Immunotherapy is a cornerstone in melanoma treatment. Adoptive cell transfer therapy (ACT) is a powerful way of improving patients' antitumor immunity via administration of $e x$ vivo activated, expanded and selected autologous tumor-reactive T cells $(50,51)$. Until today, tumor-infiltrating lymphocyte (TIL) ACT was shown to elicit an objective response of $54 \%$ and complete remission of $24 \%$ in the population of melanoma patients with extremely advanced disease who have failed multiple standard therapeutic treatments (52-54).Currently, a key problem that prevents the adoption of TIL therapy is the need to infuse a vast number of cells to generate durable results in patients $(53,55,56)$.To achieve consistent clinical responses, ACT requires administration of at least 40 to 60 billion tumor-reactive $\mathrm{T}$ cells and in some cases (57-59), up to 100 billion cells or even more (59-62), while most methods for generating vast $\mathrm{T}$ cells require 2 months or even longer (53). However, enhanced in vitro IFN- $\gamma$ releasing and cytolysis $\mathrm{CD} 8^{+} \mathrm{T}$ clones did not induce an objective clinical response upon adoptive transfer because the cytotoxic $\mathrm{CD} 8^{+} \mathrm{T}$ cells lose their antitumor efficacy when expansively expanded $e x$ vivo $(52,63,64)$. This is because $\mathrm{CD} 8+\mathrm{T}$ cells entry into a proapoptotic and replicative senescent state and have a reduced capacity to persist in vivo once they reach terminal differentiation $(51,52,65)$. Moreover, less differentiated $\mathrm{CD} 8^{+} \mathrm{T}$ cells may undergo incomplete maturation (66) or even be tolerized once encountered with the tumor specific antigen (67). Therefore, investigators focus on developing potential methods to circumvent these disadvantages by using a $\mathrm{T}$ cell subset that is refractory to senescence (52).

Chrystal M. Paulo' group found that three-week-expanded Th17 cells experienced robust growth in vitro and retained long-term eliminating melanoma efficacy with the effect of memory phenotype of $\mathrm{CD} 44^{\text {hi }} \mathrm{CD} 62 \mathrm{~L}^{\text {low }}$ in vivo, which proved to be more efficient than Th1 and 1-week-expanded Th17 cells. Furthermore, mice transferred with long-term-expanded Th17 cells were protected from melanoma rechallenge as well as lung metastasis (52). The properties that robust expansion ex vivo and persist long term in vivo of Th17 cells may partially owe to Tcf7, as it is an essential protein in the $\mathrm{Wnt} / \beta$-catenin pathway that is critical for stem memory $T$ cells self-renewal and the formation of memory daughter cells (37). Group found that the transcription factor Tcf7 was constantly present in nucleus of tumor-specific Th17 cells during expansion ex vivo (52).

Many researchers also generate Th17 cells with stemness phenotype by adding distinct cytokines or pharmacologic reagents ex vivo to enhance their antitumor efficacy. When cultured in the presence of IL-1 $\beta$, Th17 cells express high levels of IFN- $\gamma$ and exhibit enhanced antitumor effect in mice with melanoma. In addition, low doses of TGF- $\beta$ could induce stemness property of IL-1 $\beta$-cultured Th17 cells (68).

In more recent studies, Chrystal M. Paulo' laboratory demonstrated that using ROR $\gamma$ agonist LYC-55716 ex vivo or $\beta$-catenin and $\mathrm{p} 110 \delta$ inhibitors augments the antitumor activity of murine tumor-specific Th17 cells $(39,69)$. And these cells produced elevated levels of IL-17A and IFN- $\gamma$ and developed a distinct memory phenotype with elevated expression of CD44 and CD62L during response to established melanoma while untreated cells mainly presented effector

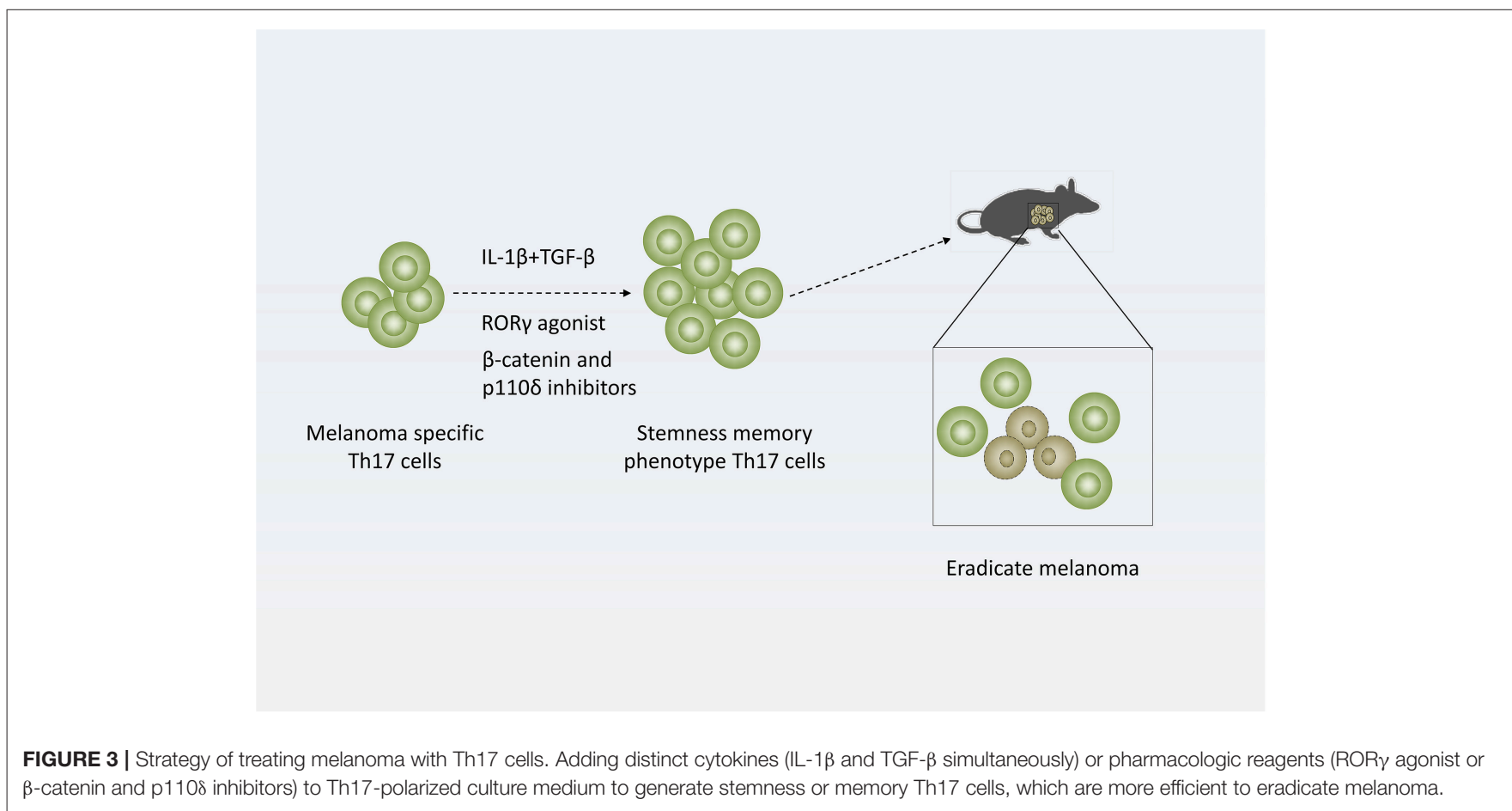


phenotypes in melanoma (69). Furthermore, mice previously infused with agonist-primed Th17 and Tc17 cells were protected from melanoma rechallenge (39). Their work suggests tumor specific Th17 cells treated with $\operatorname{ROR} \gamma$ agonist or $\beta$-catenin and $110 \delta$ inhibitors ex vivo generate potent antitumor effects and persist as long-lived memory cells. This finding implicated that adoptively transferred $\mathrm{ROR} \gamma$ agonist or $\beta$ catenin and p110 inhibitors primed Th17 cells mediate long-lived memory response protecting against melanoma (Figure 3) $(39,69)$.

\section{CONCLUSIONS}

Based on current studies, Th17 cells in a melanoma microenvironment have both antitumor and protumor effects. Whereas, adoptive transfer of tumor-specific Th17 cells into melanoma-bearing mice has been successful in eradicating established melanoma in mice, there still remains potential issues concerning the fact that Th17 may also contribute to

\section{REFERENCES}

1. Gray-Schopfer V, Wellbrock C, Marais R. Melanoma biology and new targeted therapy. Nature (2007) 445:851-7. doi: 10.1038/nature05661

2. Miller AJ, Mihm MC Jr, Melanoma. N Engl J Med. (2006) 355:51-65. doi: 10.1056/NEJMra052166

3. Bray F, Ferlay J, Soerjomataram I, Siegel RL, Torre LA, Jemal A. Global cancer statistics 2018: GLOBOCAN estimates of incidence and mortality worldwide for 36 cancers in 185 countries. CA Cancer J Clin. (2018) 68:394-424. doi: $10.3322 /$ caac. 21492

4. Miller KD, Siegel RL, Lin CC, Mariotto AB, Kramer JL, Rowland JH, et al. Cancer treatment and survivorship statistics, 2016. CA Cancer J Clin. (2016) 66:271-89. doi: 10.3322/caac.21349

5. Schadendorf D, van Akkooi ACJ, Berking C, Griewank KG, Gutzmer R, Hauschild A, et al. Melanoma. Lancet (2018) 392:971-84. doi: 10.1016/s0140-6736(18)31559-9

6. Luke JJ, Flaherty KT, Ribas A, Long GV. Targeted agents and immunotherapies: optimizing outcomes in melanoma. Nat Rev Clin Oncol. (2017) 14:463-82. doi: 10.1038/nrclinonc.2017.43

7. Eggermont AMM, Crittenden M, Wargo J. Combination immunotherapy development in melanoma. Am Soc Clin Oncol Educ Book (2018) 38:197-207. doi: 10.1200/edbk_201131

8. Flaherty KT, Infante JR, Daud A, Gonzalez R, Kefford RF, Sosman J, et al. Combined BRAF and MEK inhibition in melanoma with BRAF V600 mutations. N Engl J Med. (2012) 367:1694-703. doi: 10.1056/NEJMoa1210093

9. Yamaguchi K, Mishima K, Ohmura H, Hanamura F, Ito M, Nakano M, et al. Activation of central/effector memory $\mathrm{T}$ cells and T-helper 1 polarization in malignant melanoma patients treated with anti-programmed death-1 antibody. Cancer Sci. (2018) 109:3032-42. doi: 10.1111/cas.13758

10. Maccalli C, Giannarelli D, Capocefalo F, Pilla L, Fonsatti E, Di Giacomo AM, et al. Immunological markers and clinical outcome of advanced melanoma patients receiving ipilimumab plus fotemustine in the NIBIT-M1 study. Oncoimmunology (2016) 5:e1071007. doi: 10.1080/2162402x.2015.1071007

11. Pistillo MP, Fontana V, Morabito A, Dozin B, Laurent S, Carosio R, et al. Soluble CTLA-4 as a favorable predictive biomarker in metastatic melanoma patients treated with ipilimumab: an Italian melanoma intergroup study. Cancer Immunol Immunother. (2018) 68:97-107. doi: 10.1007/s00262-018-2258-1

12. Nardin C, Borot S, Beaudoin MA, Cattin F, Puzenat E, Gauthier AS, et al. Long-term adverse event: inflammatory orbitopathy induced by pembrolizumab in a patient with metastatic melanoma. Invest New Drugs (2018). doi: 10.1007/s10637-018-0659-9. [Epub ahead of print]. tumor growth. So further studies are required to fully explore the mechanistic effect of Th17 cells in melanoma and their therapeutic value in an adjuvant therapy approach in ACT clinical trials.

\section{AUTHOR CONTRIBUTIONS}

F-HG and CC drafted the outline of the manuscript and conducted the literature review. CC assessed the articles and wrote the manuscript. F-HG revised the manuscript. All authors have read and approved the final version of this manuscript.

\section{FUNDING}

This work was supported in part by the National Natural Science Foundation of China (81172322, 81302006, and 81572796), Shanghai Municipal Education Committee (13ZZ089), Science and Technology Committee of Shanghai (14401901500), Science and Technology Committee of Baoshan District (12-E-2).
13. Demaria S, Pikarsky E, Karin M, Coussens LM, Chen YC, El-Omar EM, et al. Cancer and inflammation: promise for biologic therapy. J Immunother. (2010) 33:335-51. doi: 10.1097/CJI.0b013e3181d32e74

14. Harrington LE, Hatton RD, Mangan PR, Turner H, Murphy TL, Murphy $\mathrm{KM}$, et al. Interleukin 17-producing CD4+ effector $\mathrm{T}$ cells develop via a lineage distinct from the T helper type 1 and 2 lineages. Nat Immunol. (2005) 6:1123-32. doi: 10.1038/ni1254

15. Park H, Li Z, Yang XO, Chang SH, Nurieva R, Wang YH, et al. A distinct lineage of $\mathrm{CD} 4 \mathrm{~T}$ cells regulates tissue inflammation by producing interleukin 17. Nat Immunol. (2005) 6:1133-41. doi: 10.1038/ni1261

16. Volpe E, Servant N, Zollinger R, Bogiatzi SI, Hupe P, Barillot E, et al. A critical function for transforming growth factor-beta, interleukin 23 and proinflammatory cytokines in driving and modulating human $\mathrm{T}(\mathrm{H})-17$ responses. Nat Immunol. (2008) 9:650-7. doi: 10.1038/ni.1613

17. Korn T, Bettelli E, Gao W, Awasthi A, Jager A, Strom TB, et al. IL-21 initiates an alternative pathway to induce proinflammatory T(H) 17 cells. Nature (2007) 448:484-7. doi: 10.1038/nature05970

18. Acosta-Rodriguez EV, Napolitani G, Lanzavecchia A, Sallusto F. Interleukins lbeta and 6 but not transforming growth factor-beta are essential for the differentiation of interleukin 17-producing human $\mathrm{T}$ helper cells. Nat Immunol. (2007) 8:942-9. doi: 10.1038/ni1496

19. Ivanov, II, McKenzie BS, Zhou L, Tadokoro CE, Lepelley A, Lafaille JJ, et al. The orphan nuclear receptor RORgammat directs the differentiation program of proinflammatory IL-17+ T helper cells. Cell (2006) 126:1121-33. doi: $10.1016 /$ j.cell.2006.07.035

20. Manel N, Unutmaz D, Littman DR. The differentiation of human $\mathrm{T}(\mathrm{H})-17$ cells requires transforming growth factor-beta and induction of the nuclear receptor RORgammat. Nat Immunol. (2008) 9:641-9. doi: 10.1038/ni.1610

21. Wilson NJ, Boniface K, Chan JR, McKenzie BS, Blumenschein WM, Mattson JD, et al. Development, cytokine profile and function of human interleukin 17producing helper T cells. Nat Immunol. (2007) 8:950-7. doi: 10.1038/ni1497

22. Stockinger B, Omenetti S. The dichotomous nature of T helper 17 cells. Nat Rev Immunol. (2017) 17:535-44. doi: 10.1038/nri.2017.50

23. Singh RP, Hasan S, Sharma S, Nagra S, Yamaguchi DT, Wong DT, et al. Th17 cells in inflammation and autoimmunity. Autoimmun Rev. (2014) 13:1174-81. doi: 10.1016/j.autrev.2014.08.019

24. Yan BY, Garcet S, Gulati N, Mitsui H, Kiecker F, Krueger JG. Immune surveillance and evasion in the progression from common melanocytic nevi to dysplastic nevi to malignant melanoma. J Investig Dermatol. (2018) 138:S202. doi: 10.1016/j.jid.2018.03.1203

25. Lim HW, Lee J, Hillsamer P, Kim CH. Human Th17 cells share major trafficking receptors with both polarized effector $\mathrm{T}$ cells 
and FOXP3+ regulatory $\mathrm{T}$ cells. $J$ Immunol. (2008) 180:122-9. doi: 10.4049/jimmunol.180.1.122

26. Su X, Ye J, Hsueh EC, Zhang Y, Hoft DF, Peng G. Tumor microenvironments direct the recruitment and expansion of human Th17 cells. J Immunol. (2010) 184:1630-41. doi: 10.4049/jimmunol.0902813

27. Wang T, Ge Y, Xiao M, Lopez-Coral A, Azuma R, Somasundaram $\mathrm{R}$, et al. Melanoma-derived conditioned media efficiently induce the differentiation of monocytes to macrophages that display a highly invasive gene signature. Pigment Cell Melanoma Res. (2012) 25:493-505. doi: 10.1111/j.1755-148X.2012.01005.x

28. Schlecker E, Stojanovic A, Eisen C, Quack C, Falk CS, Umansky V, et al. Tumor-infiltrating monocytic myeloid-derived suppressor cells mediate CCR5-dependent recruitment of regulatory T cells favoring tumor growth. $J$ Immunol. (2012) 189:5602-11. doi: 10.4049/jimmunol.1201018

29. Ortiz ML, Kumar V, Martner A, Mony S, Donthireddy L, Condamine T, et al. Immature myeloid cells directly contribute to skin tumor development by recruiting IL-17-producing CD4+ T cells. J Exp Med. (2015) 212:351-67. doi: $10.1084 /$ jem.20140835

30. Korn T, Bettelli E, Oukka M, Kuchroo VK. IL-17 and Th17 Cells. Annu Rev Immunol. (2009) 27:485-517. doi: 10.1146/annurev.immunol.021908.132710

31. Guruvayoorappan C, Kuttan G. Apoptotic effect of Biophytum sensitivum on B16F-10 cells and its regulatory effects on nitric oxide and cytokine production on tumor-associated macrophages. Integr Cancer Ther. (2007) 6:373-80. doi: 10.1177/1534735407309484

32. Bailey SR, Nelson MH, Himes RA, Li Z, Mehrotra S, Paulos CM. Th17 cells in cancer: the ultimate identity crisis. Front Immunol. (2014) 5:276. doi: $10.3389 /$ fimmu. 2014.00276

33. Kryczek I, Banerjee M, Cheng P, Vatan L, Szeliga W, Wei S, et al. Phenotype, distribution, generation, and functional and clinical relevance of Th17 cells in the human tumor environments. Blood (2009) 114:1141-9. doi: 10.1182/blood-2009-03-208249

34. Ankathatti Munegowda M, Deng Y, Mulligan SJ, Xiang J. Th17 and Th17stimulated CD8(+) T cells play a distinct role in Th17-induced preventive and therapeutic antitumor immunity. Cancer Immunol Immunother. (2011) 60:1473-84. doi: 10.1007/s00262-011-1054-y

35. Kollgaard T, Ugurel-Becker S, Idorn M, Andersen MH, Becker JC, Straten PT. Pre-vaccination frequencies of Th17 cells correlate with vaccine-induced T-cell responses to survivin-derived peptide epitopes. PLoS ONE (2015) 10:e0131934. doi: 10.1371/journal.pone.0131934

36. Muranski P, Boni A, Antony PA, Cassard L, Irvine KR, Kaiser A, et al. Tumor-specific Th17-polarized cells eradicate large established melanoma. Blood (2008) 112:362-73. doi: 10.1182/blood-2007-11-120998

37. Muranski P, Borman ZA, Kerkar SP, Klebanoff CA, Ji Y, Sanchez-Perez L, et al. Th17 cells are long lived and retain a stem cell-like molecular signature. Immunity (2011) 35:972-85. doi: 10.1016/j.immuni.2011.09.019

38. Martin-Orozco N, Muranski P, Chung Y, Yang XO, Yamazaki T, Lu S, et al. $\mathrm{T}$ helper 17 cells promote cytotoxic $\mathrm{T}$ cell activation in tumor immunity. Immunity (2009) 31:787-98. doi: 10.1016/j.immuni.2009.09.014

39. Hu X, Majchrzak K, Liu X, Wyatt MM, Spooner CJ, Moisan J, et al. In vitro priming of adoptively transferred $\mathrm{T}$ cells with a rorgamma agonist confers durable memory and stemness in vivo. Cancer Res. (2018) 78:3888-98. doi: 10.1158/0008-5472.can-17-3973

40. Holderfield M, Deuker MM, McCormick F, McMahon M. Targeting RAF kinases for cancer therapy: BRAF-mutated melanoma and beyond. Nat Rev Cancer (2014) 14:455-67. doi: 10.1038/nrc3760

41. Spivey TL, De Giorgi V, Zhao Y, Bedognetti D, Pos Z, Liu Q, et al. The stable traits of melanoma genetics: an alternate approach to target discovery. BMC Genomics (2012) 13:156. doi: 10.1186/1471-2164-13-156

42. Tomei S, Civini S, Bedognetti D, De Giorgi V, Reinboth J, Ascierto ML, et al. The immune-related role of braf mutation in melanoma. J Immunother. (2012) 35:788-9. doi: 10.1097/CJI.0b013e318272bdd9

43. Tomei S, Bedognetti D, De Giorgi V, Sommariva M, Civini S, Reinboth J, et al. The immune-related role of BRAF in melanoma. Mol Oncol. (2015) 9:93-104. doi: 10.1016/j.molonc.2014.07.014

44. Hayata K, Iwahashi M, Ojima T, Katsuda M, Iida T, Nakamori M, et al. Inhibition of IL-17A in tumor microenvironment augments cytotoxicity of tumor-infiltrating lymphocytes in tumor-bearing mice. PLoS ONE (2013) 8:e53131. doi: 10.1371/journal.pone.0053131
45. Wang L, Yi T, Kortylewski M, Pardoll DM, Zeng D, Yu H. IL-17 can promote tumor growth through an IL-6-Stat3 signaling pathway. J Exp Med. (2009) 206:1457-64. doi: 10.1084/jem.20090207

46. Koenen HJ, Smeets RL, Vink PM, van Rijssen E, Boots AM, Joosten I. Human CD25highFoxp3pos regulatory T cells differentiate into IL-17-producing cells. Blood (2008) 112:2340-52. doi: 10.1182/blood-2008-01-133967

47. Valmori D, Raffin C, Raimbaud I, Ayyoub M. Human RORgammat+ TH17 cells preferentially differentiate from naive FOXP3+Treg in the presence of lineage-specific polarizing factors. Proc Natl Acad Sci USA. (2010) 107:194027. doi: $10.1073 /$ pnas. 1008247107

48. Ye J, Livergood RS, Peng G. The role and regulation of human Th17 cells in tumor immunity. Am J Pathol. (2013) 182:10-20. doi: 10.1016/j.ajpath.2012.08.041

49. Hoechst B, Gamrekelashvili J, Manns MP, Greten TF, Korangy F. Plasticity of human Th17 cells and iTregs is orchestrated by different subsets of myeloid cells. Blood (2011) 117:6532-41. doi: 10.1182/blood-2010-11-317321

50. Rosenberg SA. Cell transfer immunotherapy for metastatic solid cancerwhat clinicians need to know. Nat Rev Clin Oncol. (2011) 8:577-85. doi: $10.1038 /$ nrclinonc.2011.116

51. Gattinoni L, Klebanoff CA, Palmer DC, Wrzesinski C, Kerstann K, Yu Z, et al. Acquisition of full effector function in vitro paradoxically impairs the in vivo antitumor efficacy of adoptively transferred CD8+ T cells. J Clin Invest. (2005) 115:1616-26. doi: $10.1172 /$ jci2 4480

52. Bowers JS, Nelson MH, Majchrzak K, Bailey SR, Rohrer B, Kaiser AD, et al. Th17 cells are refractory to senescence and retain robust antitumor activity after long-term ex vivo expansion. JCI Insight (2017) 2:e90772. doi: $10.1172 /$ jci.insight. 90772

53. Merhavi-Shoham E, Itzhaki O, Markel G, Schachter J, Besser MJ. Adoptive cell therapy for metastatic melanoma. Cancer J. (2017) 23:48-53. doi: 10.1097/ppo.0000000000000240

54. Phan GQ, Rosenberg SA. Adoptive cell transfer for patients with metastatic melanoma: the potential and promise of cancer immunotherapy. Cancer Control. (2013) 20:289-97. doi: 10.1177/107327481302000406

55. Wu R, Forget MA, Chacon J, Bernatchez C, Haymaker C, Chen JQ, et al. Adoptive T-cell therapy using autologous tumor-infiltrating lymphocytes for metastatic melanoma: current status and future outlook. Cancer J. (2012) 18:160-75. doi: 10.1097/PPO.0b013e31824d4465

56. Radvanyi LG, Bernatchez C, Zhang M, Fox PS, Miller P, Chacon J, et al. Specific lymphocyte subsets predict response to adoptive cell therapy using expanded autologous tumor-infiltrating lymphocytes in metastatic melanoma patients. Clin Cancer Res. (2012) 18:6758-70. doi: 10.1158/1078-0432.ccr-12-1177

57. Besser MJ, Shapira-Frommer R, Itzhaki O, Treves AJ, Zippel DB, Levy $D$, et al. Adoptive transfer of tumor-infiltrating lymphocytes in patients with metastatic melanoma: intent-to-treat analysis and efficacy after failure to prior immunotherapies. Clin Cancer Res. (2013) 19:4792-800. doi: 10.1158/1078-0432.ccr-13-0380

58. Kvistborg P, Shu CJ, Heemskerk B, Fankhauser M, Thrue CA, Toebes $\mathrm{M}$, et al. TIL therapy broadens the tumor-reactive CD8(+) $\mathrm{T}$ cell compartment in melanoma patients. Oncoimmunology (2012) 1:409-18. doi: $10.4161 /$ onci.18851

59. Forget MA, Tavera RJ, Haymaker C, Ramachandran R, Malu S, Zhang M, et al. A novel method to generate and expand clinical-grade, genetically modified, tumor-infiltrating lymphocytes. Front Immunol. (2017) 8:908. doi: 10.3389/fimmu.2017.00908

60. Chapuis AG, Thompson JA, Margolin KA, Rodmyre R, Lai IP, Dowdy K, et al. Transferred melanoma-specific CD8+ $\mathrm{T}$ cells persist, mediate tumor regression, and acquire central memory phenotype. Proc Natl Acad Sci USA. (2012) 109:4592-7. doi: 10.1073/pnas.1113748109

61. Radvanyi LG. Tumor-infiltrating lymphocyte therapy: addressing prevailing questions. Cancer J. (2015) 21:450-64. doi: 10.1097/ppo.00000000000 00162

62. Rohaan MW, van den Berg JH, Kvistborg P, Haanen J. Adoptive transfer of tumor-infiltrating lymphocytes in melanoma: a viable treatment option. $J$ Immunother Cancer (2018) 6:102. doi: 10.1186/s40425-018-0391-1

63. Rosenberg SA, Restifo NP. Adoptive cell transfer as personalized immunotherapy for human cancer. Science (2015) 348:62-8. doi: $10.1126 /$ science.aaa4967 
64. Majchrzak K, Nelson MH, Bailey SR, Bowers JS, Yu XZ, Rubinstein $\mathrm{MP}$, et al. Exploiting IL-17-producing $\mathrm{CD} 4+$ and $\mathrm{CD} 8+\mathrm{T}$ cells to improve cancer immunotherapy in the clinic. Cancer Immunol Immunother. (2016) 65:247-59. doi: 10.1007/s00262-0161797-6

65. Klebanoff CA, Gattinoni L, Restifo NP. Sorting through subsets: which T-cell populations mediate highly effective adoptive immunotherapy? J Immunother. (2012) 35:651-60. doi: 10.1097/CJI.0b013e31827806e6

66. Mortarini R, Piris A, Maurichi A, Molla A, Bersani I, Bono A, et al. Lack of terminally differentiated tumor-specific CD8+ T cells at tumor site in spite of antitumor immunity to self-antigens in human metastatic melanoma. Cancer Res. (2003) 63:2535-45.

67. Willimsky G, Blankenstein T. Sporadic immunogenic tumours avoid destruction by inducing T-cell tolerance. Nature (2005) 437:141-6. doi: $10.1038 /$ nature 03954

68. Chatterjee S, Thyagarajan K, Kesarwani P, Song JH, Soloshchenko M, Fu J, et al. Reducing CD73 expression by IL1beta-Programmed Th17 cells improves immunotherapeutic control of tumors. Cancer Res. (2014) 74:604859. doi: 10.1158/0008-5472.can-14-1450

69. Majchrzak K, Nelson MH, Bowers JS, Bailey SR, Wyatt MM, Wrangle JM, et al. beta-catenin and PI3Kdelta inhibition expands precursor Th17 cells with heightened stemness and antitumor activity. JCI Insight (2017) 2:e90547. doi: 10.1172/jci.insight.90547

Conflict of Interest Statement: The authors declare that the research was conducted in the absence of any commercial or financial relationships that could be construed as a potential conflict of interest.

Copyright $(9) 2019$ Chen and Gao. This is an open-access article distributed under the terms of the Creative Commons Attribution License (CC BY). The use, distribution or reproduction in other forums is permitted, provided the original author(s) and the copyright owner(s) are credited and that the original publication in this journal is cited, in accordance with accepted academic practice. No use, distribution or reproduction is permitted which does not comply with these terms. 